\title{
A NOTE ON THE PATTERNS OF QUANTITATIVE SEROLOGICAL TESTS IN LATE SYPHILIS*

\author{
BY
}

\author{
A. REDMOND, C. S. NICOL, and R. A. SHOOTER
}

From St. Bartholomew's Hospital, London

Since January, 1949, all patients with late syphilis attending the Special Treatment Centre of St. Bartholomew's Hospital have had quantitative Wassermann reactions performed on their sera before and after treatment. 83 patients have been investigated by monthly tests for a minimum of 6

* Received for publication January 2, 1952 months and in many cases for 2 years or more. The results have been charted in graphic form and incorporated in the patients' case notes, as advocated by Price (1949).

\section{Technique}

The same Wassermann technique was employed by the same technician throughout the investigation, the

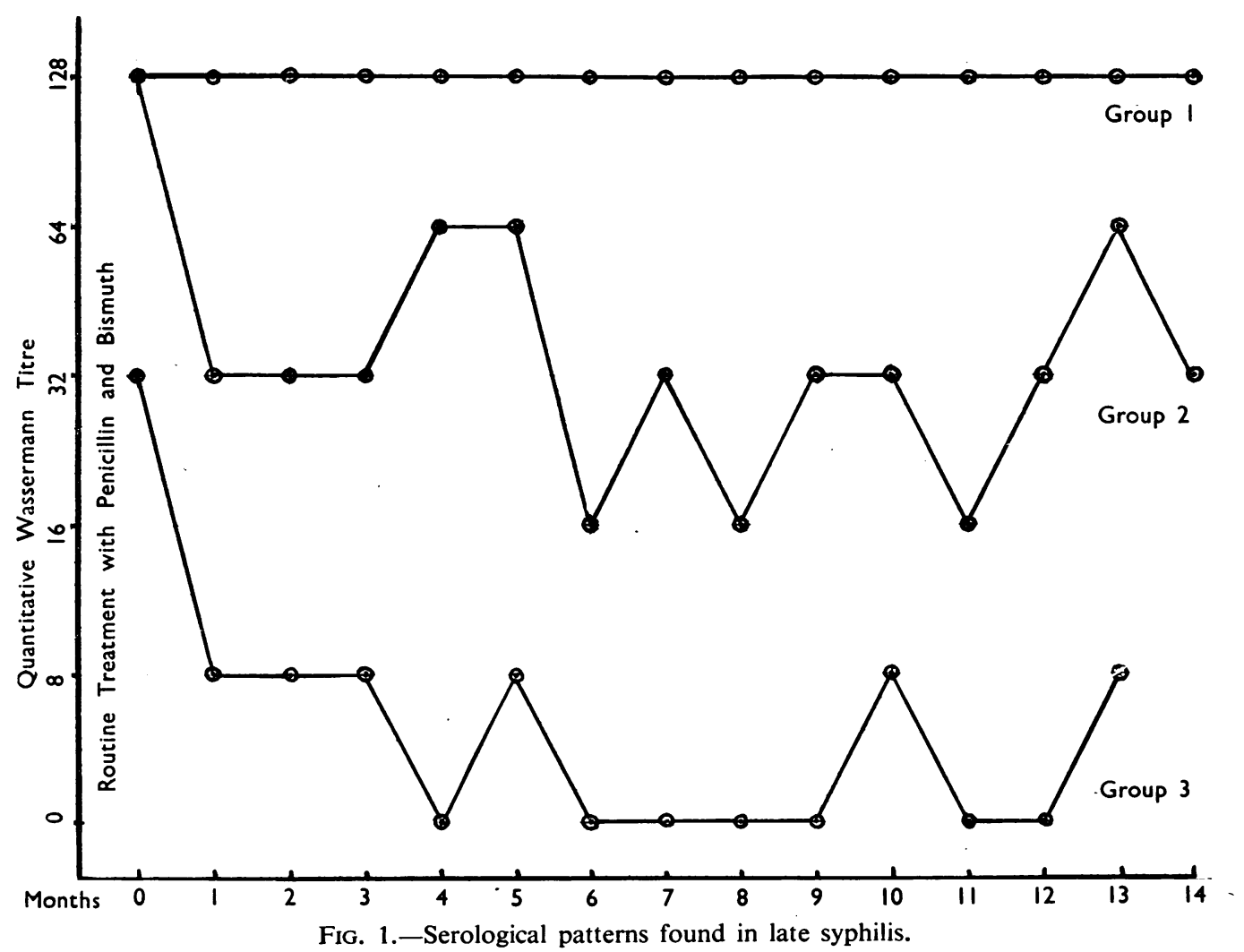


titres being reported as the highest serum dilution showing fixation. To economize labour, routine titrations were only taken to a serum dilution of 1 in 128 .

\section{Results}

Three main serological patterns were found :

Group 1.-Those in which the titre remained consistently high, at a minimum level of 1 in 128 .

Group 2.-Those in which the titre fluctuated but never reached sero-negativity. Patients were only included in this group if the variation was at least three dilutions, as it is usually accepted that a difference in titre of one or even two dilutions in consecutive quantitative tests may be produced by slight day-to-day variations in the sensitivity of the test.

Group 3.-Those in which there was a progressively declining titre which might reach seronegativity and might then oscillate between a negative and a low positive titre.

Representative cases illustrating these three Groups are shown in Fig. 1 (previous page).

Of the 83 patients with fully treaced late syphilis (acquired or congenital), nine showed the pattern of Group 1, 49 of Group 2, and 25 of Group 3. Details of the sex and diagnosis of these patients are given in the Table.

\section{Discussion}

There seems to be no significant difference in the serological patterns of the acquired and congenital
TABLE

DISTRIBUTION OF SEROLOGICAL PATTERNS IN LATE SYPHILIS

\begin{tabular}{c|c|c|c|c|c|c}
\hline Diagnosis & \multicolumn{2}{|c|}{ Acquired } & \multicolumn{2}{c|}{ Congenital } & \multicolumn{2}{c}{ Total } \\
\hline Group & Male & Female & Male & Female & No. & $\%$ \\
\hline 1 & 4 & 2 & 2 & 1 & 9 & 10 \\
2 & 22 & 21 & 2 & 4 & 49 & 60 \\
3 & 10 & 12 & 1 & 2 & 25 & 30 \\
\hline Total & 36 & 35 & 5 & 7 & 83 & 100 \\
\hline
\end{tabular}

types of late syphilis, nor did the sex of the patient apparently have any effect on the pattern. However, the numbers in some of the groups are too small to be dogmatic about these points.

If it is accepted that there is a true fluctuation in the amount of reagin from time to time in some cases, it is of interest to know whether the change is gradual or rapid. Blood was therefore taken from one patient with a fluctuating titre, first at weekly, and then at daily intervals. The titres are shown graphically in Fig. 2. The results show that this particular patient's titre did not vary by more than one dilution during the 7 weeks that these tests were continued, a variation within the limits of laboratory error. Daily tests were also carried out on a patient with a Group 1 pattern; the results (Fig. 3), show no significant variation over a period of 7 days. The findings in these two patients therefore suggest that any change in the level of reagin in this type of case is gradual.

The effect of re-treatment on the titre of an already adequately treated patient is shown in

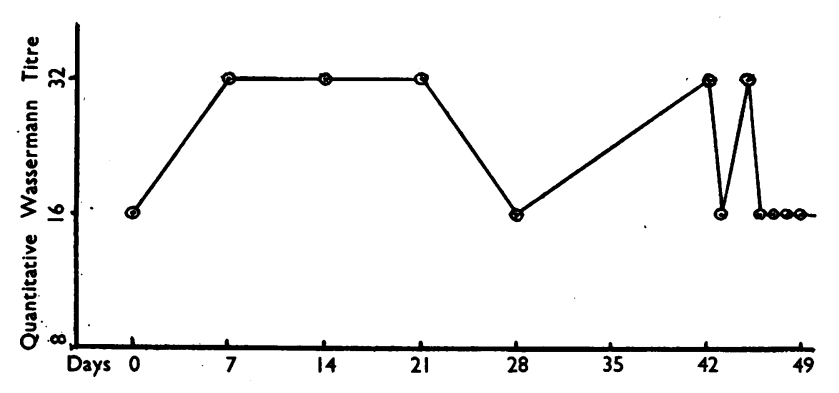

FIG. 2.-Fluctuation in reagin over a 7-week period (Group 2 pattern).

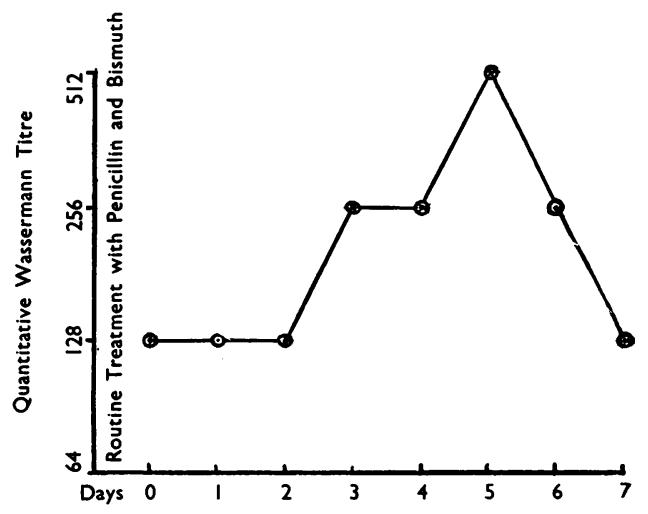

FIG. 3.-Daily fluctuation in reagin (Group 1'pattern). 
SEROLOGICAL TESTS IN LATE SYPHILIS

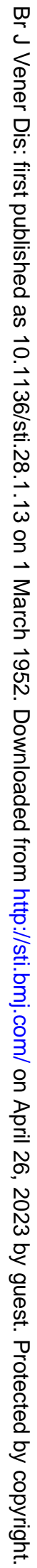

Fig. 4. The titre remained unchanged for the 4 months in which the patient was observed after retreatment. It appears that once the reagin-forming mechanism has been stimulated by infection over a period of years, reagin may continue to be present in the blood in varying amounts despite adequate treatment.

It seems reasonable to suggest that the reagin level may fluctuate in untreated cases and that there may be considerable danger in accepting a single negative serum test as excluding infection in any patient suspected of having late acquired or late congenital syphilis.

We are indebted to Mr. Vidler for technical help.

REFERENCE

Price, I. N. Orpwood (1949). British Journal of Venereal Diseases, 25, 67.

B 